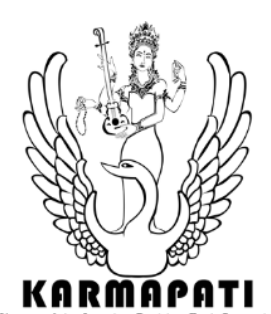

e-ISSN: 2685-7006|p-ISSN: $2252-9063$

Kumpulan Artikel Mahasiswa Pendidikan Teknik Informatika

(KARMAPATI)

Volume 10, Nomor 1, Tahun 2021

\title{
Pengembangan Media Pembelajaran Augmented Reality Book 2 Dimensi Sub Tema Lingkungan Alam di PAUD Telkom Singaraja
}

\author{
Made Kevin Ihza Mahendra ${ }^{1}$, I Gede Partha Sindu ${ }^{2}$, Gede Hendra Divayana ${ }^{3}$ \\ Program Studi Pendidikan Teknik Informatika \\ Universitas Pendidikan Ganesha \\ Singaraja, Indonesia \\ kefine.ihza@gmail.com ${ }^{1}$, partha.sindu@undiksha.ac.id ${ }^{2}$, hendra.divayana@ undiksha.ac.id $^{\mathbf{3}}$
}

\begin{abstract}
The purpose of Development The Media Learning Augmented Reality Book 2 Dimensions With The Natural Environment Theme In PAUD Telkom Singaraja is to develop 2dimensional Augmented Reality learning media sub-theme of the natural environment on the Android platform, as a medium to facilitate the learning process and provide attractiveness in understanding the natural environment. The development of 2-dimensional Augmented Reality learning media with the sub-theme of the natural environment uses the ADDIE model which consists of stages, namely the analysis, design, development, implementation and evaluation stages. In this model, an evaluation process is carried out at each stage that is passed so as to produce learning media that suits the needs of PAUD Telkom Singaraja. The end result of this development is in the form of 2dimensional Augmented Reality learning media with a sub-theme of the natural environment that can be used via mobile devices with the Android operating system. The black box and white box tests were carried out accordingly, the content expert test and the media test got a value of 1.00 in the very high category, the individual test got an average value of $94,22 \%$ in the very good category, the small group test got an average score of $94,44 \%$ with very good category student response, field test $92.89 \%$ with very good category and teacher response 90,66\% with very good category.
\end{abstract}

Keywords: 2-dimensional Augmented Reality, Natural Disasters, Early Childhood Education

\section{PENDAHULUAN}

PAUD Telkom Singaraja merupakan PAUD yang berada di Kabupaten Buleleng, Provinsi Bali. Sistem pendidikan di PAUD Telkom Singaraja, kegiatan pembelajaran dikelas terbagi menjadi 9 metode yakni bercerita, bercakap-cakap, tanya jawab, karyawisata, demonstrasi, bermain peran, eksperimen, proyek, dan pemberian tugas. Berdasarkan Permendiknas Republik Indonesia Nomor 16 tahun 2007 tentang standar kompetensi guru PAUD/TK/RA yang tercantum pada kompetensi pedagogi, menuntut guru untuk memanfaatkan teknologi informasi dan komunikasi untuk kepentingan penyelenggaraan kegiatan pengembangan yang mendidik. Paparan di atas menunjukkan bahwa kemajuan teknologi menjadi tuntunan guru untuk mengembangkan kompetensi peserta didik di era globalisasi. Adanya perkembangan teknologi informasi yang pesat, maka media pembelajaran juga harus bisa dikembangkan menjadi kreatif, interaktif, menyenangkan, yang membuat media pembelajaran menjadi lebih modern. Salah satu tema yang terdapat di PAUD Telkom yaitu pengenalan teknologi. Anak didik PAUD Telkom mewajibkan peserta didik belajar mengenai teknologi sehingga media pembelajaran yang modern dapat diterapkan dengan baik.

Media pembelajaran yang digunakan guru untuk proses pembelajaran di PAUD Telkom berupa papan flanel dan media cetak bergambar. Tetapi untuk Tema Lingkungan Alam dengan spesifikasi tema Gejala Alam tidak terdapat media yang membantu proses pembelajaran. Padahal media pembelajaran memiliki fungsi sebagai alat untuk membuat pembelajaran yang lebih efektif, mempercepat proses belajar, meningkatkan kualitas proses belajar mengajar, memperjelas yang abstrak sehingga dapat mengurangi terjadinya penyakit verbalisme [13]. Berdasarkan manfaat media pembelajaran, Media pembelajaran penting digunakan di PAUD Telkom Singaraja untuk dapat membantu kemudahan belajar bagi siswa dan kemudahan mengajar bagi guru.

Perkembangan teknologi informasi semakin berkembang. Dunia Pendidikan Perkembangan IPTEK terhadap proses pembelajaran adalah diperkayanya sumber belajar dan beragam media pembelajaran. Salah satu media pembelajaran dengan pemanfaatan teknologi yaitu media pembelajaran berbasis 


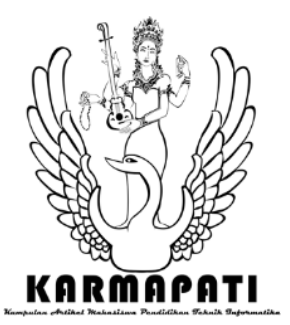

Augmented reality. Berdasarkan pengamatan peneliti penggunaan media pembelajaran berbasis Augmented reality para siswa PAUD Telkom Singaraja tertarik menggunakan media digital. Terbuktinya dengan memberi siswa PAUD Telkom Singaraja contoh media digital berbasis Augmented reality. Beberapa penelitian sebelumnya yang pernah menyinggung hal ini adalah pengembangan media pembelajaran Augmented reality pembelajaran organ pencernaan [16] yang menyatakan penerapan Augmented Reality mampu merealisasikan dunia virtual ke dunia nyata, dapat menampilkan objek gambar 2 dimensi tersebut menjadi objek 3 dimensi, sehingga metode pembelajaran tidaklah monoton dan para siswa siswi jadi terpacu untuk mengetahuinya lebih lanjut, mengetahui bentuk dan visualisasi nama organ yang menyerupai bentuk aslinya dan penejlasan masing-masing organ pencernaan tersebut. Penelitian lain yang dilakukan [2] pengembangan media pembelajaran Augmented reality mengenai jaringan komputer berbasis Augmented Reality hasil akhir penelitian menunjukkan bahwa, respons ahli isi dan respons ahli media menyatakan modul dan aplikasi layak uji coba lapangan, serta respons siswa terhadap pengembangan Modul Ajar Interaktif Berbasis Augmented Reality sangat baik dengan persentase $91 \%$.

Berdasarkan permasalahan dan penjelasan di atas, maka peneliti mencoba untuk membangun sebuah media pembelajaran berbasis Augmented Reality Book, diharapkan proses pembelajaran yang dilalui oleh peserta didik menjadi lebih interaktif dan menyenangkan, maka penelitian mengembangkan sebuah media pembelajaran berbasis Augmented Reality Book yang menampilkan animasi $2 \mathrm{D}$ dengan sub tema Lingkungan Alam spesifikasi gejala alam serta penjelasan menggunakan voice over yang berjudul "Pengembangan Media Pembelajaran Augmented Reality Book 2 Dimensi Sub Tema Lingkungan Alam di PAUD Telkom Singaraja”.

\section{KAJIAN TEORI}

\section{A. Media Pembelajaran}

Media Pembelajaran merupakan bentuk jamak kata "medium" yang secara harfiah berarti pengantar atau perantara. Media adalah berbagai jenis komponen lingkungan siswa yang dapat merangsang para siswa untuk belajar Gagne [19]. Pada pengertian lain, media adalah sesuatu yang bisa digunakan untuk menyampaikan pesan dari pengirim pesan ke penerima [14]. Berdasarkan 2 pendapat terlihat pengertian media mengarah pada penggunaan alat yang berupa benda dan membantu proses
e-ISSN: 2685-7006 |p-ISSN: 2252-9063

Kumpulan Artikel Mahasiswa Pendidikan Teknik Informatika

(KARMAPATI)

Volume 10, Nomor 1, Tahun 2021 penyampaian pesan. Asosiasi Pendidikan Nasional (Nation Education Association/ NEA) memberikan batasan tentang media yaitu bentuk-bentuk komunikasi baik tercetak maupun audio visual serta berbagai peralatannya. Menurut undang-undang republik Indonesia nomor 20 tahun 2003 tentang sistem pendidikan nasional, Pembelajaran adalah proses interaksi peserta didik dengan pendidik dan sumber belajar pada suatu lingkungan belajar.

\section{B. Augmented Reality}

Augmented Reality adalah teknologi masa sekarang yang menggabungkan benda maya (tidak nyata) dua dimensi 2D ataupun tiga dimensi 3D ke sebuah lingkungan nyata secara langsung, tiga dimensi kemudian memberikan gambaran bendabenda maya yang tersedia waktu nyata. Realitas maya, virtual reality yang sepenuhnya menggantikan keadaan nyata, namun Augmented Reality hanya menambahkan objek atau animasi dan melengkapi kenyataan. Augmented Reality Book (AR Book) dalam bahasa Indonesia berarti buku yang berbasis augmented reality merupakan penggabungan antara media buku berisikan gambar marker dengan teknologi Augmented Reality. AR-Book memiliki dua komponen utama, yaitu media buku dengan dilengkapi dengan marker setiap halaman yang ingin diberi teknologi AR, dan kedua peralatan kamera handphone untuk menangkap marker dan menampilkan hasilnya. Augmented Reality Book termasuk salah satu sumber untuk pembelajaran yang di buat khusus, karena dikembangkan untuk mempermudah guru atau siswa memahami isi buku dengan cara mengeluarkan animasi, suara, melihatkan objek dua dimensi atau tiga dimensi pada gambar yang tertera pada buku.[15]

\section{Animasi Dua Dimensi}

Animasi dua dimensi dikenal juga dengan nama animasi datar atau flat animation. Model animasi 2D dibuat dan/atau diedit di komputer menggunakan gambar bitmap 2D, atau dibuat dan diedit menggunakan gambar vektor 2D Animasi ini termasuk versi teknik animasi tradisional yang terotomatisasi pada komputer, misalnya tweening, morphing, onion skinning, dan interpolated rotoscoping (Binanto, 2010). Film kartun juga biasa dikenal dengan animasi 2D. Kartun berasal dari kata Cartoon, yang artinya gambar yang lucu dan menarik. Film kartun itu kebanyakan film yang lucu. Contohnya Tom and Jerry, Re: Zero, Konosuba, Doraemon[3].

\section{Voice Over}




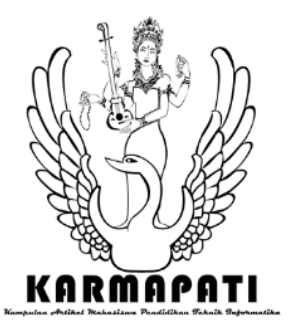

Voice-over adalah suara yang dapat berkomunikasi tanpa pengisi suara yang terlihat, suara yang digunakan biasanya pada radio, televisi, film, multimedia, atau dunia bisnis (Wright, 2009). Voice over di media bertujuan sebagai pembawa informasi, berfungsi Informatif atau menghibur. Naskah yang baik akan sangat membantu proses penyampaian pesan, Voice Over juga perlu mempunyai kemampuan membaca atau menerjemahkan naskah yang baik sesuai media yang akan digunakan. Karena masingmasing media mempunyai karakter sendiri yang berbedabeda[22]

\section{E. Android}

Android adalah salah satu sistem operasi open source yang digunakan untuk perangkat layar sentuh. SDK atau software development kit merupakan sebuah kit yang berfungsi untuk mengembangkan berbagai aplikasi berbasis android oleh para developer [23]. Di SDK terdapat berbagai tools yang bertujuan untuk proses pengembangan aplikasi.

\section{F. Vuforia}

Vuforia merupakan salah satu perangkat lunak yang dikembangkan untuk membantu pembuatan Augmented Reality. Dibuat bentuk SDK, vuforia memiliki kemampuan untuk melakukan pengenalan citra perkembangan image recognition[16]. Terdapat dua jenis workflow dengan dasar basis data yang dapat dipilih oleh pengembang, yaitu basis data melalui jaringan dan Device Database.

\section{G. Unity}

Unity merupakan salah satu software game engine, Game Engine adalah sebuah sistem yang dirancang untuk penciptaan dan pengembangan video game [21]. Mesin game terkemuka menyediakan kerangka kerja perangkat lunak yang digunakan untuk pengembang membuat game untuk konsol permainan video dan komputer pribadi. Fungsionalitas inti biasanya dipersiapkan oleh play machine mencakup render machine untuk $2 \mathrm{D}$ atau $3 \mathrm{D}$ grafis, voice over, code, animasi, artificial intelegent, jaringan, streaming, memori manajemen, threading, lokalisasi dukungan, dan scene grafik

\section{H. After Effect}

Adobe after effect adalah program video editing untuk mengolah kreasi efek video menjadi lebih menarik [20].Program ini sangat popular dan banyak digunakan oleh animator karena
e-ISSN: 2685-7006 | p-ISSN: $2252-9063$

Kumpulan Artikel Mahasiswa Pendidikan Teknik Informatika

(KARMAPATI)

Volume 10, Nomor 1, Tahun 2021 fasilitas dan kemampuan program mengolah video disbanding dengan program lain yang sejenis. Selain memiliki beragam kreasi efek, program ini memberi kemudahan mengolah animasi..

\section{METODOLOGI PENELITIAN}

Pengembangan Media Pembelajaran Augmented Reality Book 2 Dimensi Sub Tema Lingkungan Alam di PAUD Telkom Singaraja penelitian menggunakan metode Penelitian dan Pengembangan atau Research and Development. $R \& D$ (Research and Development) dideskripsikan sebagai metode penelitian yang digunakan untuk menghasilkan suatu produk serta menguji keefektifan dari produk yang dibuat.

Produk yang dibuat tidak selalu harus berbentuk benda, modul, buku, alat bantu untuk menunjang pembelajaran di kelas atau laboratorium, tetapi memungkinkan berupa perangkat lunak (software), program komputer untuk pengolahan data, pembelajaran dikelas, perpustakaan atau laboratorium, ataupun model-model pendidikan, pembelajaran, pelatihan, bimbingan, evaluasi, sistem manajemen.[17].

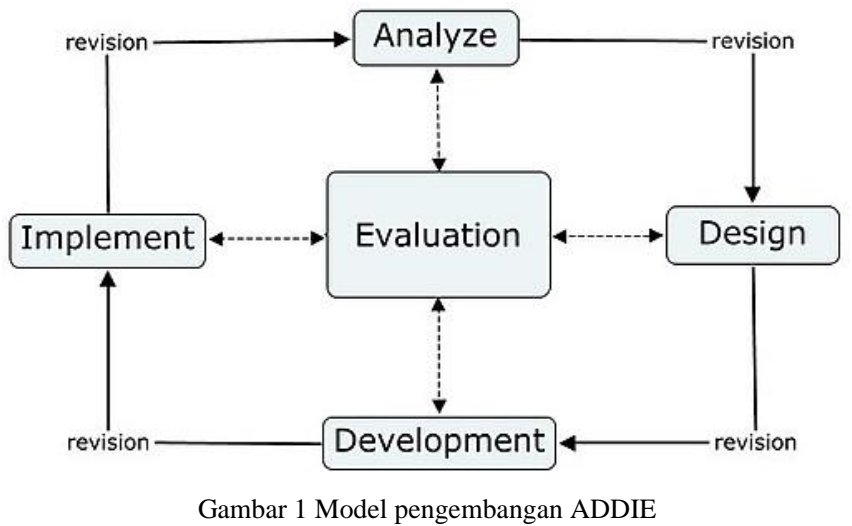

1. Analysis

Pra perencanaan: sebelum mendesain melakukan pemikiran tentang produk (model, metode, media, bahan ajar) baru yang akan dikembangkan memperhatikan produk yang sesuai dengan sasaran peserta didik, tujuan belajar, memperhatikan isi/materi pembelajaran, memperhatikan lingkungan belajar dan strategi penyampaian pembelajaran

2. Design

Merancang konsep produk baru di atas kertas Merancang perangkat pengembangan produk baru. Rancangan ditulis untuk masing-masing unit pembelajaran. Petunjuk 


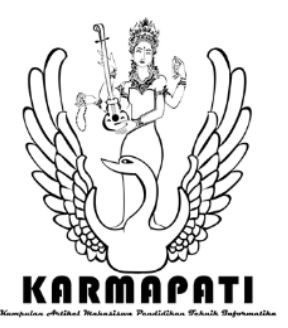

penerapan design atau pembuatan media ditulis secara jelas.

3. Develop

Mengembangkan perangkat media (materi/bahan dan alat) yang dibutuhkan pengembangan berbaris pada hasil rancangan produk, pada tahap ini mulai dibuat medianya (materi/bahan dan alat) yang sesuai dengan struktur model Membuat instrumen untuk mengukur kinerja produk

4. Implementation

Memulai menggunakan produk baru pembelajaran atau lingkungan yang nyata Melihat kembali tujuan-tujuan pengembangan produk, interaksi antar peserta didik serta menanyakan umpan balik awal proses evaluasi

5. Evaluation

Melihat kembali setiap tahap dampak pembelajaran dengan cara yang kritis Mengukur ketercapaian tujuan pengembangan produk Mengukur apa yang telah mampu dicapai oleh Mencari informasi apa saja yang dapat membuat peserta didik mencapai hasil dengan baik

\section{HASIL DAN PEMBAHASAN}

A. Analisis

Tahap ini dijelaskan mengenai analisis masalah dan solusi, analisis modul buku digital, serta analisis perangkat lunak.

a. Analisis Masalah dan Usulan Solusi

Berdasarkan tahap analisis yang dilakukan peneliti dengan melakukan wawancara pada tanggal 18 Januari 2020, media pembelajaran yang digunakan berupa papan flanel dan media bahan cetak tetapi tidak terdapat media pembelajaran untuk tema lingkungan alam dengan spesifikasi tema gejala alam. Guru hanya menggunakan metode bercakap-cakap. Berdasarkan permasalahan tersebut perlu adanya pengembangan media pembelajaran. Berdasarkan data yang diperoleh selanjutnya peneliti akan merancang penanganan yang efektif dengan mengembangkan media pembelajaran Augmented Reality Book 2 dimensi sub tema lingkungan alam di PAUD Telkom Singaraja.

b. Analisis Modul Ajar Buku Digital

9 dari 12 Materi pembelajaran / indikator berbeda yang terdapat di RPPH (Terlampir) akan digunakan pembuatan media pembelajaran berbasis Augmented Reality
e-ISSN: 2685-7006 | p-ISSN: $2252-9063$

Kumpulan Artikel Mahasiswa Pendidikan Teknik Informatika

(KARMAPATI)

Volume 10, Nomor 1, Tahun 2021
1) Mengetahui adanya Tuhan

2) Berdoa sebelum dan sesudah kegiatan

3) Merespons saat di dengar, yang menceritakan kembali apa yang sudah didengar

4) Membaca gambar/mengenal huruf

5) Mendengar kan dan Alunan lagu

6) Berteman/ bekerja sama

7) Mencocok bilangan dan lambang bilangan

8) Percobaan dengan benda-benda di sekitar

9) Bereksplorasi dengan berbagai bahan untuk membuat hasil karya

9 indikator yang dicapai terdapat tujuan pembelajaran diantarinya

1) Anak dapat menyebutkan ciptaan-ciptaan tuhan : hujan, petir, tsunami, gunung meletus

2) Anak dapat mengucapkan doa-doa pendek melalui kegiatan berdoa sebelum dan sesudah kegiatan

3) Anak dapat menceritakan dan merespons Kembali apa yang didengar

4) Anak dapat menunjukkan bentuk-bentuk simbol dan menulis huruf dengan baik

5) Anak dapat mendengarkan alunan lagu melalui kegiatan bernyanyi

6) Anak dapat bekerja sama dengan teman

7) Anak dapat mengenal benda dengan menghubungkan gambar dengan angka dan mengenal lambang bilangan

8) Melalui dengan percobaan dengan menggunakan benda di sekitar anak dapat mengetahui tekstur, warna, fungsi, ciri-ciri

9) Anak dapat membuat karya seni sesuai kreativitasnya menggambar

c. Analisis Kebutuhan Perangkat Lunak

Kebutuhan perangkat lunak dapat dikategorikan menjadi 2 bagian sebagai kebutuhan fungsional dan non-fungsional. Kebutuhan fungsional dan non-fungsional aplikasi yang akan dibangun peneliti :

Kebutuhan Fungsional, diantarinya aplikasi dapat mendeteksi marker yang ada pada Buku Augmented Reality Gejala Alam, aplikasi mampu memulai aplikasi, aplikasi mampu menampilkan video animasi 2 dimensi (2D) Gejala Alam, aplikasi dapat mengeluarkan suara Voice Over.

Kebutuhan Non-Fungsional, diantarinya media pembelajaran yang dibangun harus memiliki materi yang sesuai dengan materi pelajaran, aplikasi yang akan dibuat dapat 


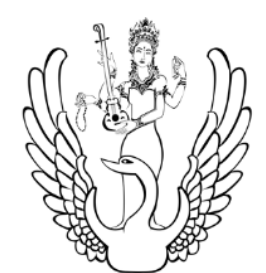

e-ISSN: 2685-7006|p-ISSN: 2252-9063

Kumpulan Artikel Mahasiswa Pendidikan Teknik Informatika

(KARMAPATI)

Volume 10, Nomor 1, Tahun 2021

\section{KARMAPATI}

menampilkan visualisasi simulasi objek 2D dengan teknik Augmented Reality, aplikasi yang dibangun harus interaktif dan edukatif agar memudahkan pengguna memahami materi.

\section{d. Tujuan Pengembangan Perangkat Lunak}

Tujuan pengembangan media pembelajaran materi lingkungan alam sebagai media pembelajaran bagi siswa dan guru yang bisa diterapkan pada smartphone mereka agar dapat mempermudah pemahaman materi lingkungan alam.

\section{e. Masukan dan Keluaran Perangkat Lunak}

Masukan media pembelajaran Augmented Reality Book 2 dimensi Sub Tema Lingkungan Alam di PAUD Telkom Singaraja adalah penanda/marker untuk memunculkan animasi 2 dimensi. Sedangkan keluaran media pembelajaran Augmented Reality Book 2 dimensi Sub Tema Lingkungan Alam di PAUD Telkom Singaraja adalah animasi objek 2 dimensi mengenai lingkungan alam.

\section{Desain}

Sesuai dengan model yang digunakan oleh peneliti yaitu ADDIE, setelah tahap analisis dilakukan tahapan selanjutnya yaitu tahap design untuk membuat rancangan media pembelajaran Augmented Reality Book 2 dimensi Sub Tema Lingkungan Alam di PAUD Telkom Singaraja. Pada tahap ini peneliti melakukan proses perancangan model fungsional perangkat lunak, perancangan perangkat lunak.

a. Perancangan Model Fungsional

1) Flowchart

Perancangan model fungsional menggunakan Proses flowchart adalah metode yang digunakan untuk mempresentasikan bentuk bagan alur serangkaian peristiwa-peristiwa proses atau layanan yang diberikan. Flowchart merupakan alat yang fleksibel yang memungkinkan sebuah anggota tim meneliti proses yang kompleks mengidentifikasi bidang masalah potensial dan peluang bagi peningkatan.

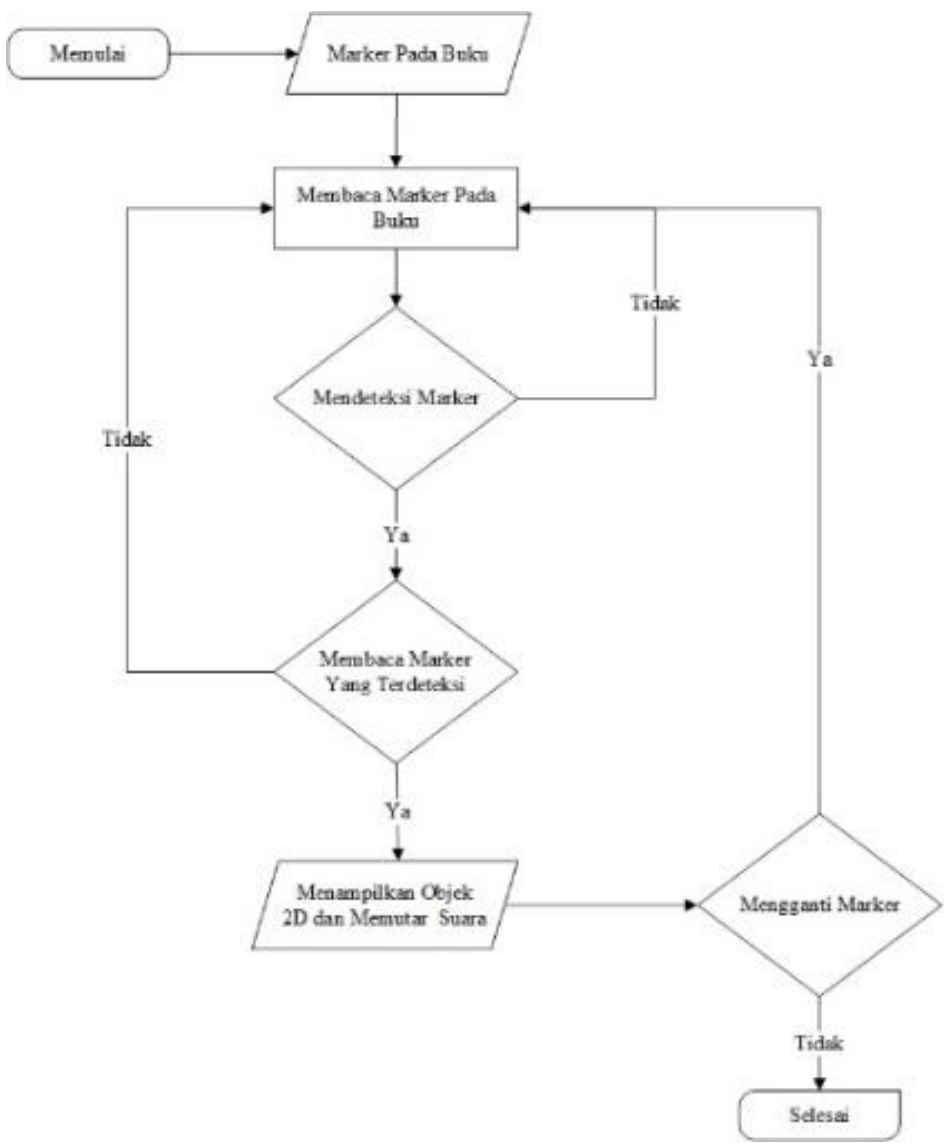

Gambar 2 Flowchart Rancangan Model Fungsional

b. Perancangan Perangkat lunak

Batasan Perancangan Perangkat Lunak tema alam spesifikasi gejala alam yang akan di implementasikan ke media pembelajaran Augmented Reality yaitu mengenai gejala alam hujan, gempa bumi, tsunami dan gunung meletus. Agar penggunaan media pembelajaran Augmented Reality lebih efektif media tidak hanya menyampaikan mengenai gejala alam tetapi mengambil beberapa bagian RPPH mengikuti alunan lagu dan membuat kerajinan.

1. Rancangan buku 
e-ISSN: 2685-7006 |p-ISSN: 2252-9063

Kumpulan Artikel Mahasiswa Pendidikan Teknik Informatika

(KARMAPATI)

Volume 10, Nomor 1, Tahun 2021

\section{KดRMAPดTI}

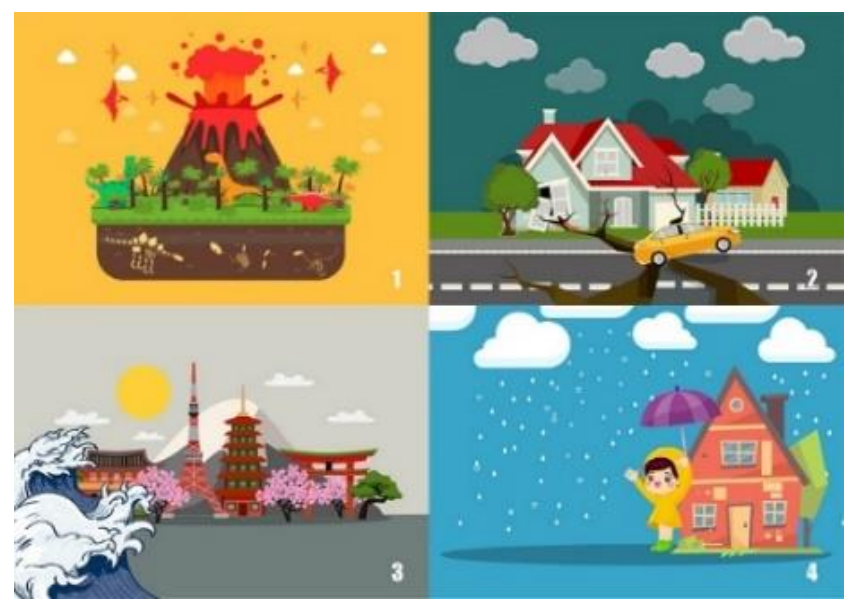

Gambar 3 Rancangan Buku Bagian Memahami

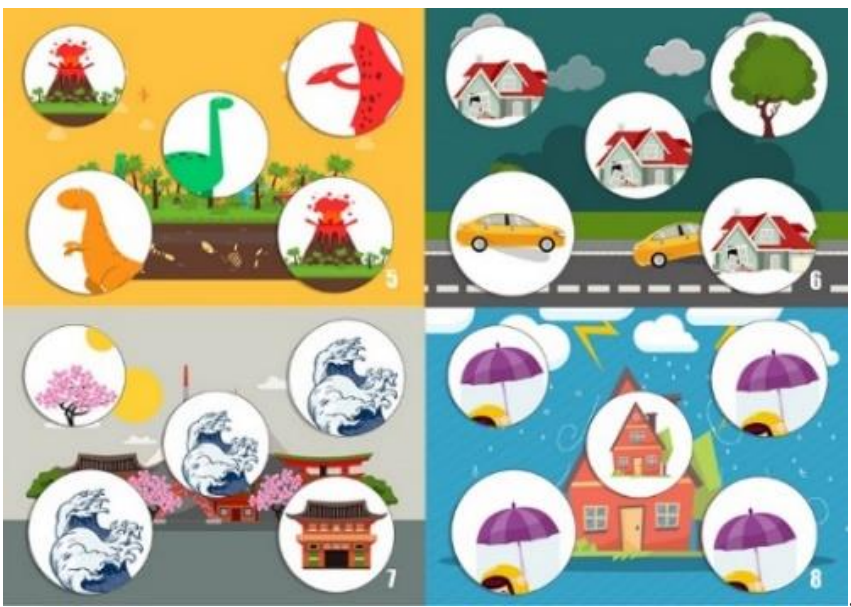

Gambar 4 Rancangan Buku Bagian Quiz

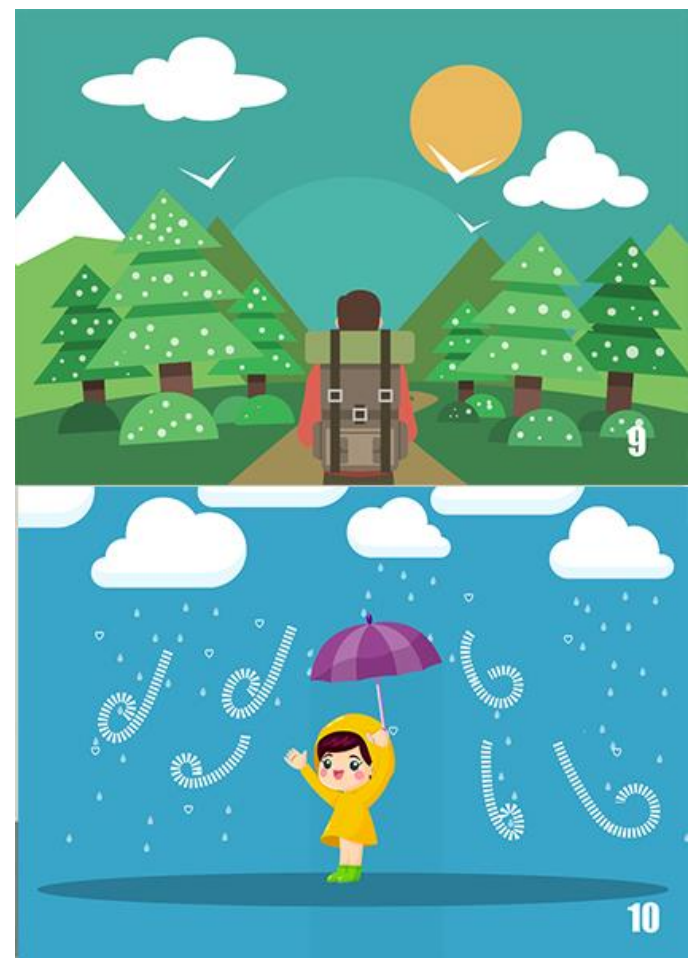

Gambar 5 Rancangan Buku Bagian Lagu

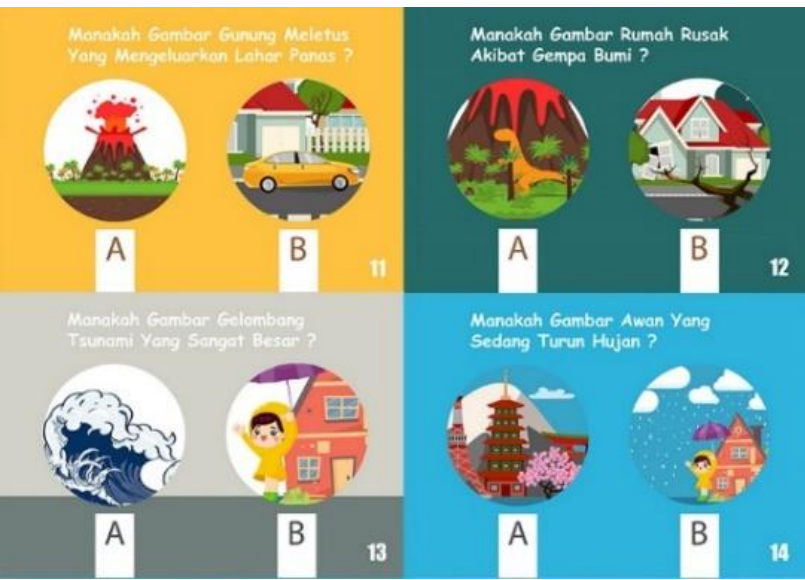

Gambar 6 Rancangan Buku Bagian Quiz 

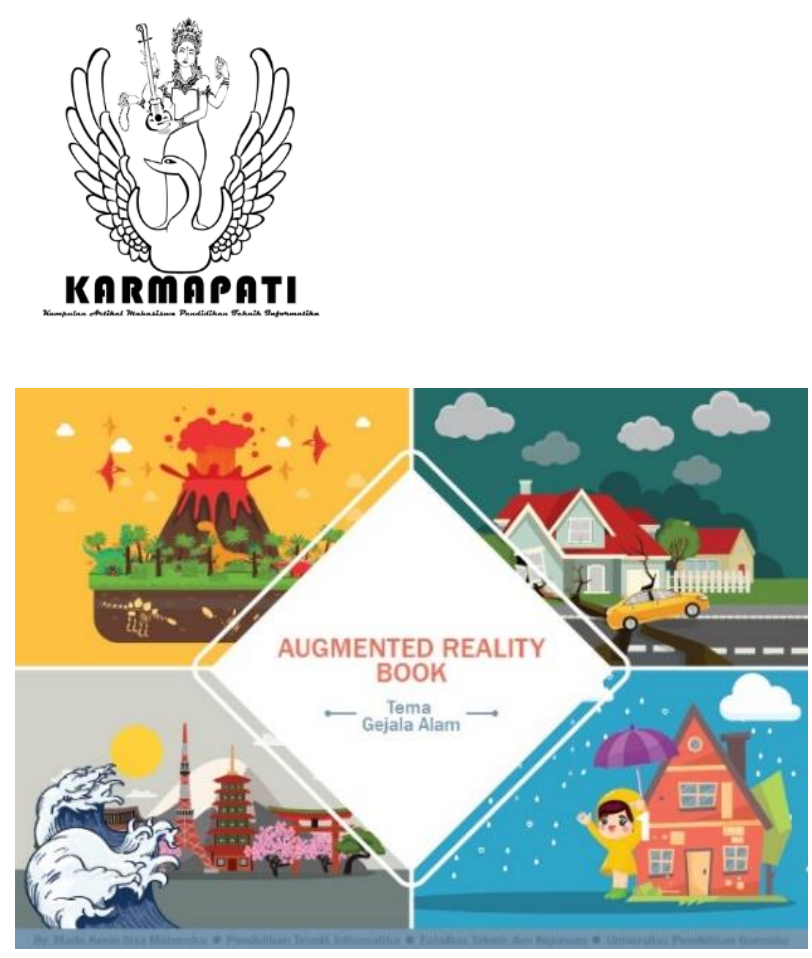

Gambar 7 Rancangan Buku Bagian Cover

\section{Pengembangan}

Development menggunakan model ADDIE berisi kegiatan realisasi rancangan produk. Pengembangan media pembelajaran menggunakan model ADDIE. Hasil pengembangan media pembelajaran berbasis augmented reality book materi gejala alam dapat dilihat pada gambar 7, 8 dan 9 .

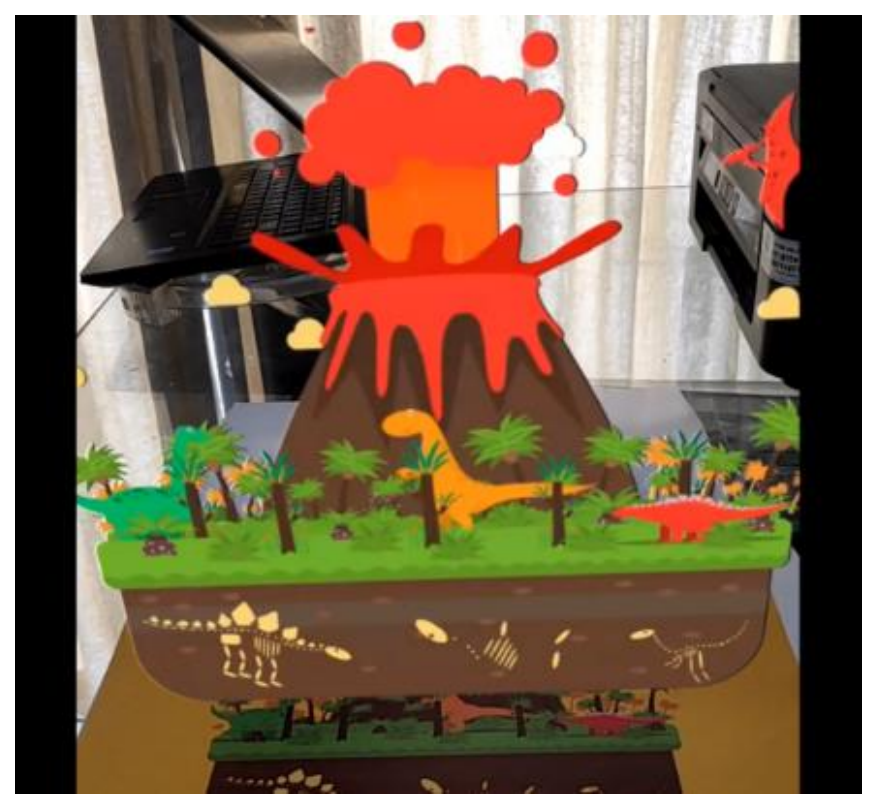

Gambar 8 Execute Program
e-ISSN: 2685-7006|p-ISSN: 2252-9063

Kumpulan Artikel Mahasiswa Pendidikan Teknik Informatika

(KARMAPATI)

Volume 10, Nomor 1, Tahun 2021

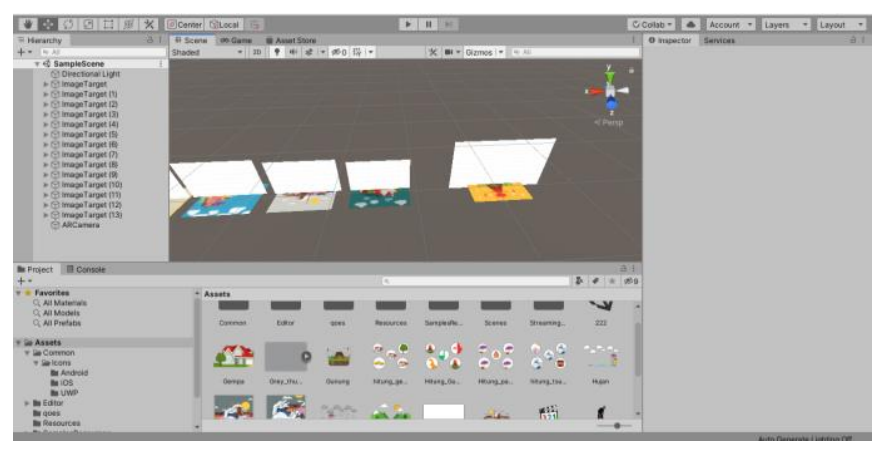

Gambar 9 Pengembangan Media

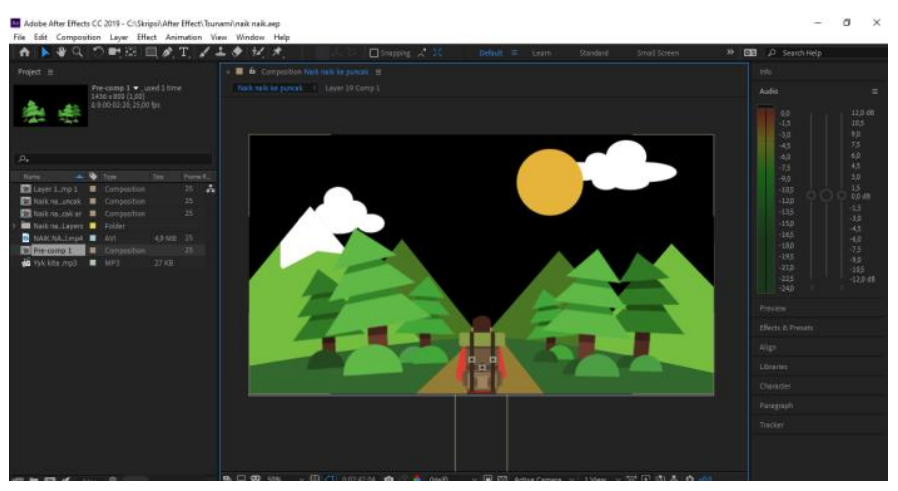

Gambar 10 Pembuatan Animasi

\section{Implementasi}

Media pembelajaran bisa digunakan sebagai sumber dan media belajar disekolah media harus dikatakan valid, untuk itu media harus mengalami proses validasi uji ahli terlebih dahulu. Pengembangan media Augmented Reality Book 2 Dimensi sudah mengalami pengujian para ahli. Pengujian yang dilakukan oleh ahli adalah uji ahli isi dan uji ahli media. Selain pengujian ahli isi dan ahli media juga dilakukan pengujian kepada siswa, yaitu uji lapangan.

\section{1) Uji White Box}

Uji white box pengujian dilakukan dengan menelusuri kode program untuk menemukan kesalahan. Pengujian dilakukan secara bertahap saat implementasi mulai awal pembuatan aplikasi sampai aplikasi selesai dibuat. Menggunakan teknik Basis-path testing dengan tahapan sebagai berikut: 


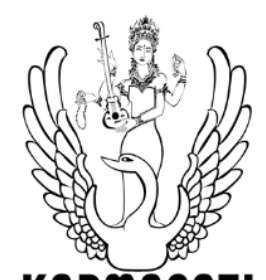

KดRMAPดTI

a) Pembuatan flowgraph berdasarkan flowchart yang telah dibuat

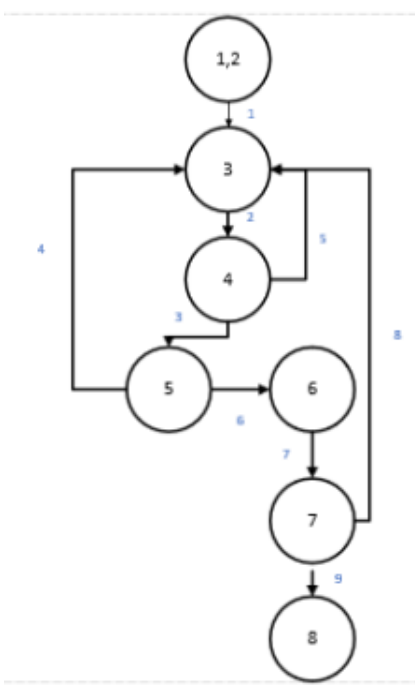

Gambar 4. 1 Gambar flowgraph

b) cyclometic complexity

Diketahui : $\mathrm{E}=8, \mathrm{~N}=9$

Ditanya : $\mathrm{V}(\mathrm{G})=$ ?

Jawab: $\mathrm{V}(\mathrm{G})=\mathrm{E}-\mathrm{N}+2=8-9+2=1$

Jadi nilai $\mathrm{V}(\mathrm{G})$ atau $\mathrm{CC}$ adalah 1 .

Nilai $V(G)$ atau $C C$ diperlukan untuk mengetahui jumlah independen path yang dapat dibuat pada tahap selanjutnya.

c) Independent Path

Nilai $\mathrm{cc}=1$ maka independen path hanya 1 yaitu 1 2,3,4,5,6,7,8,9 Berdasarkan independen path dapat dilihat bahwa node awal dan node akhir sudah terhubung dan semua edge sudah dilalui. Hal ini adalah syarat sebuah independen path. Independent path kemudian diimplementasikan bentuk test case dengan cara mengganti angka pada jalur dengan keterangan untuk setiap Node. Kemudian dilakukan pengujian sesuai aksi pada test case tersebut.

d) Test case

Kasus uji atau test case dibuat untuk mengeksekusi semua alur logika yang telah dirancang. Setelah dijalankan, maka akan dapat diketahui apakah hasil pengujian sesuai atau tidak dengan yang diharapkan. Berikut ini adalah test case yang telah dibuat berdasarkan path :

1. Memulai aplikasi
e-ISSN: 2685-7006 | p-ISSN: 2252-9063

Kumpulan Artikel Mahasiswa Pendidikan Teknik Informatika

(KARMAPATI)

Volume 10, Nomor 1, Tahun 2021
2. Menyediakan marker pada buku

3. Membaca marker pada buku

4. Mendeteksi marker

5. Membaca marker yang terdeteksi

6. Menampilkan animasi 2D dengan suara

7. Mengganti marker

8. Selesai

Semua test case dengan kasus uji 8 sudah sesuai, Pengujian whitebox telah selesai dan dapat diperoleh hasil bahwa aplikasi dapat berjalan sesuai dengan yang diharapkan.

\section{2) Black Box}

Pengujian black box dilakukan setelah aplikasi selesai dibuat dengan menggunakan metode pengujian test case black box.. Berdasarkan hasil pengujian test case black box tersebut, dapat disimpulkan bahwa aplikasi dapat berjalan dengan baik dan semua fungsi dapat berjalan dengan baik sesuai dengan yang diharapkan[9].

\section{3) Pengujian Alpha}

Pengujian alpha testing adalah tahap pengujian yang bertujuan untuk identifikasi dan mengetahui kelayakan media pembelajaran yang telah dibuat [4]. Revisi terhadap media pembelajaran ini dilakukan sesuai saran dan komentar ahli isi dan media yang mendapatkan nilai dengan kategori sangat tinggi yang dihitung menggunakan Gregory[24].

\section{Tabel 1 tabel gregory}

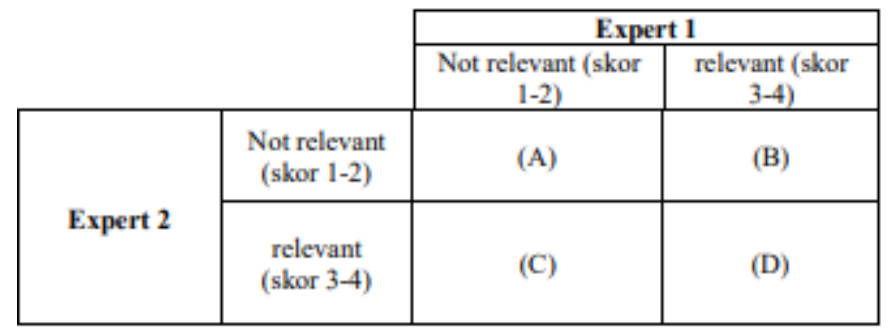

Tabel 2 Validasi Uji Ahli Isi

\begin{tabular}{|c|c|c|c|}
\hline $\begin{array}{c}\text { Nomor Butir } \\
\text { Pernyataan }\end{array}$ & Ahli 1 & Ahli 2 & Keterangan \\
\hline 1 & Relevan & Relevan & D \\
\hline 2 & Relevan & Relevan & D \\
\hline 3 & Relevan & Relevan & D \\
\hline 4 & Relevan & Relevan & D \\
\hline 5 & Relevan & Relevan & D \\
\hline 6 & Relevan & Relevan & D \\
\hline
\end{tabular}




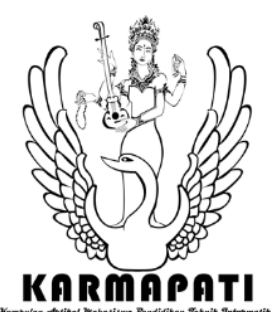

e-ISSN: 2685-7006 | p-ISSN: 2252-9063

Kumpulan Artikel Mahasiswa Pendidikan Teknik Informatika

(KARMAPATI)

Volume 10, Nomor 1, Tahun 2021

\begin{tabular}{|c|c|c|c|}
\hline $\begin{array}{c}\text { Nomor Butir } \\
\text { Pernyataan }\end{array}$ & Ahli 1 & Ahli 2 & Keterangan \\
\hline 7 & Relevan & Relevan & D \\
\hline 8 & Relevan & Relevan & D \\
\hline 9 & Relevan & Relevan & D \\
\hline 10 & Relevan & Relevan & D \\
\hline 11 & Relevan & Relevan & D \\
\hline 12 & Relevan & Relevan & D \\
\hline \multicolumn{3}{|c|}{ JUMLAH A } & $\mathbf{0}$ \\
\hline JUMLAH B & $\mathbf{0}$ \\
\hline JUMLAH C & $\mathbf{1 2}$ \\
\hline
\end{tabular}

Tabel 3 Validasi Uji Ahli Media

\begin{tabular}{|c|c|c|c|}
\hline $\begin{array}{l}\text { Nomor Butir } \\
\text { Pernyataan }\end{array}$ & Ahli 1 & Ahli 2 & Keterangan \\
\hline 1 & Relevan & Relevan & $\mathrm{D}$ \\
\hline 2 & Relevan & Relevan & $\mathrm{D}$ \\
\hline 3 & Relevan & Relevan & $\mathrm{D}$ \\
\hline 4 & Relevan & Relevan & $\mathrm{D}$ \\
\hline 5 & Relevan & Relevan & $\mathrm{D}$ \\
\hline 6 & Relevan & Relevan & $\mathrm{D}$ \\
\hline 7 & Relevan & Relevan & $\mathrm{D}$ \\
\hline 8 & Relevan & Relevan & $\mathrm{D}$ \\
\hline 9 & Relevan & Relevan & $\mathrm{D}$ \\
\hline 10 & Relevan & Relevan & $\mathrm{D}$ \\
\hline 11 & Relevan & Relevan & $\mathrm{D}$ \\
\hline 12 & Relevan & Relevan & $\mathrm{D}$ \\
\hline 13 & Relevan & Relevan & $\mathrm{D}$ \\
\hline 14 & Relevan & Relevan & $\mathrm{D}$ \\
\hline 15 & Relevan & Relevan & $\mathrm{D}$ \\
\hline 16 & Relevan & Relevan & $\mathrm{D}$ \\
\hline 17 & Relevan & Relevan & $\mathrm{D}$ \\
\hline 18 & Relevan & Relevan & $\mathrm{D}$ \\
\hline 19 & Relevan & Relevan & $\mathrm{D}$ \\
\hline 20 & Relevan & Relevan & $\mathrm{D}$ \\
\hline \multicolumn{3}{|c|}{ JUMLAH A } & $\mathbf{0}$ \\
\hline \multicolumn{3}{|c|}{ JUMLAH B } & $\mathbf{0}$ \\
\hline \multicolumn{3}{|c|}{ JUMLAH C } & $\mathbf{0}$ \\
\hline \multicolumn{3}{|c|}{ JUMLAH D } & 20 \\
\hline
\end{tabular}

4) Pengujian Beta

Pengujian Beta dilakukan secara objektif, pengujian beta dilakukan secara langsung terhadap pengguna, biasanya menggunakan kuesioner mengenai tanggapan pengguna atas media pembelajaran yang dibangun. Tujuan pengujian beta yaitu untuk mengetahui penilaian pengguna terhadap media yang telah dibangun, pada pengujian ini dilakukan oleh Guru PAUD Telkom Singaraja. Analisis respons guru dan peserta didik bertujuan untuk mengetahui respons guru dan peserta didik terhadap media pembelajaran yang telah dikembangkan dengan menyebarkan angket kepada guru. Pada penelitian respons peserta didik akan diamati oleh guru

Validasi Perorangan membandingkan data persentase keseluruhan subyek maka dapat disimpulkan bahwa Media Pembelajaran berbasis augmented reality book Pada spesifikasi tema gejala alam dapat dikatakan berhasil atau Sangat Baik mendukung proses pembelajaran. Detail instrumen hasil pengujian dapat dilihat pada Lampiran 9. Subjek uji coba perorangan adalah 3 orang siswa kelas A. Hasil angket uji coba yang diisi oleh ketiga siswa, terdapat masing-masing siswa memberikan tanggapan cukup baik yaitu 97,33\%, 93,33\% dan $92 \%$. Rata-rata penilaian ketiga orang siswa adalah $94,22 \%$. Jika dikonversikan ke dalam tabel respon siswa termasuk kategori sangat baik.

\begin{tabular}{|c|c|c|c|}
\multicolumn{4}{|c|}{ Tabel 4 validasi Perorangan } \\
\hline \multirow{2}{*}{ pernyataan } & \multicolumn{3}{|c|}{ responden } \\
\cline { 2 - 4 } & $\mathbf{1}$ & $\mathbf{2}$ & $\mathbf{3}$ \\
\hline 1 & 5 & 5 & 5 \\
\hline 2 & 5 & 5 & 5 \\
\hline 3 & 5 & 5 & 4 \\
\hline 4 & 5 & 5 & 5 \\
\hline 5 & 5 & 5 & 4 \\
\hline 6 & 5 & 5 & 5 \\
\hline 7 & 5 & 5 & 5 \\
\hline 8 & 5 & 5 & 5 \\
\hline 9 & 5 & 5 & 5 \\
\hline 10 & 5 & 4 & 4 \\
\hline 11 & 5 & 3 & 3 \\
\hline 12 & 4 & 3 & 5 \\
\hline 13 & 4 & 5 & 5 \\
\hline 14 & 5 & 5 & 5 \\
\hline 15 & 5 & 5 & 4 \\
\hline Jumlah & 73 & 70 & 69 \\
\hline Persentase & $97,33 \%$ & $93,33 \%$ & $92 \%$ \\
\hline & & & \\
\hline
\end{tabular}

Validasi Kelompok kecil Rata - rata hasil persentase yang diperoleh keseluruhan 94,44\% dapat disimpulkan bahwa media pembelajaran berbasis augmented reality book pada mata pelajaran gejala alam dapat dikatakan berhasil atau sangat baik mendukung proses pembelajaran. Detail angket hasil pengujian tersedia pada lampiran 12 Subjek uji coba kelompok kecil adalah 6 orang siswa kelas B. Hasil angket uji coba yang diisi oleh ke enam siswa yang diobservasi orang tua siswa, terdapat masingmasing siswa memberikan tanggapan baik. Jika dikonversikan ke dalam tabel respon siswa termasuk kategori sangat baik 
: 2685-7006|p-ISSN: 2252-9063

Kumpulan Artikel Mahasiswa Pendidikan Teknik Informatika

(KARMAPATI)

Volume 10, Nomor 1, Tahun 2021

\section{KARMAPATI}

Tabel 5 validasi Kelompok Kecil

\begin{tabular}{|c|c|c|c|}
\hline \multirow{2}{*}{ pernyataan } & \multicolumn{3}{|c|}{ Responden } \\
\cline { 2 - 4 } & $\mathbf{1}$ & $\mathbf{2}$ & $\mathbf{3}$ \\
\hline 1 & 5 & 5 & 5 \\
\hline 2 & 5 & 5 & 5 \\
\hline 3 & 4 & 5 & 5 \\
\hline 4 & 5 & 5 & 5 \\
\hline 5 & 4 & 4 & 5 \\
\hline 6 & 5 & 5 & 5 \\
\hline 7 & 5 & 5 & 5 \\
\hline 8 & 5 & 5 & 5 \\
\hline 9 & 5 & 5 & 5 \\
\hline 10 & 5 & 4 & 5 \\
\hline 11 & 5 & 4 & 5 \\
\hline 12 & 5 & 4 & 4 \\
\hline 13 & 4 & 5 & 4 \\
\hline 14 & 5 & 5 & 5 \\
\hline 15 & 5 & 5 & 5 \\
\hline Jumlah & 72 & 71 & 73 \\
\hline Persentase & $96 \%$ & $94,66 \%$ & $97,33 \%$ \\
\hline
\end{tabular}

\begin{tabular}{|c|c|c|}
\hline \multicolumn{3}{|c|}{ Responden } \\
\hline $\mathbf{4}$ & $\mathbf{5}$ & $\mathbf{6}$ \\
\hline 5 & 5 & 5 \\
\hline 5 & 5 & 5 \\
\hline 5 & 4 & 5 \\
\hline 5 & 5 & 5 \\
\hline 5 & 4 & 5 \\
\hline 5 & 5 & 5 \\
\hline 5 & 5 & 5 \\
\hline 5 & 5 & 5 \\
\hline 5 & 5 & 5 \\
\hline 4 & 4 & 4 \\
\hline 3 & 3 & 3 \\
\hline 3 & 5 & 4 \\
\hline 5 & 5 & 4 \\
\hline 5 & 5 & 5 \\
\hline 5 & 4 & 5 \\
\hline 70 & 69 & 70 \\
\hline $93,33 \%$ & $92 \%$ & $93,33 \%$ \\
\hline
\end{tabular}

Validasi lapangan hasil persentase yang diperoleh keseluruhan subjek dapat disimpulkan bahwa media pembelajaran berbasis augmented reality pada spesifikasi tema gejala alam dapat dikatakan berhasil atau sangat baik mendukung proses pembelajaran. Detail angket hasil pengujian tersedia pada lampiran 13. Subjek uji respon perorangan yaitu seluruh siswa kelas A yang berjumlah 15. Masing-masing siswa memberikan tanggapan sangat baik terhadap media yang dikembangkan yaitu sebanyak 15 orang. Rata-rata penilaian semua siswa adalah $92,89 \%$.
Tabel 6 validasi Lapangan

\begin{tabular}{|c|c|c|c|c|c|}
\hline \multirow{2}{*}{ pernyataan } & \multicolumn{5}{|c|}{ Responden } \\
\hline & 1 & 2 & 3 & 4 & 5 \\
\hline 1 & 5 & 5 & 5 & 5 & 5 \\
\hline 2 & 5 & 5 & 5 & 5 & 5 \\
\hline 3 & 3 & 4 & 5 & 5 & 4 \\
\hline 4 & 5 & 4 & 5 & 5 & 5 \\
\hline 5 & 4 & 5 & 5 & 5 & 4 \\
\hline 6 & 5 & 5 & 5 & 5 & 5 \\
\hline 7 & 5 & 5 & 5 & 5 & 5 \\
\hline 8 & 5 & 5 & 5 & 5 & 5 \\
\hline 9 & 5 & 5 & 5 & 5 & 5 \\
\hline 10 & 3 & 3 & 4 & 4 & 4 \\
\hline 11 & 3 & 4 & 3 & 3 & 3 \\
\hline 12 & 3 & 4 & 3 & 3 & 4 \\
\hline 13 & 5 & 4 & 5 & 5 & 5 \\
\hline 14 & 5 & 4 & 5 & 4 & 5 \\
\hline 15 & 4 & 4 & 5 & 5 & 4 \\
\hline Jumlah & 65 & 66 & 70 & 69 & 68 \\
\hline Persentase & $\begin{array}{l}86, \\
67 \\
\%\end{array}$ & $\begin{array}{c}88 \\
\%\end{array}$ & $\begin{array}{c}93, \\
33 \\
\%\end{array}$ & $\begin{array}{l}92 \\
\%\end{array}$ & $\begin{array}{c}90, \\
67 \\
\%\end{array}$ \\
\hline
\end{tabular}

\begin{tabular}{|c|c|c|c|c|c|}
\hline \multirow{2}{*}{ pernyataan } & \multicolumn{5}{|c|}{ Responden } \\
\cline { 2 - 6 } & $\mathbf{6}$ & $\mathbf{7}$ & $\mathbf{8}$ & $\mathbf{9}$ & $\mathbf{1 0}$ \\
\hline 1 & 5 & 5 & 5 & 5 & 5 \\
\hline 2 & 5 & 5 & 5 & 5 & 5 \\
\hline 3 & 5 & 4 & 5 & 5 & 4 \\
\hline 4 & 5 & 5 & 5 & 5 & 5 \\
\hline 5 & 5 & 4 & 4 & 5 & 4 \\
\hline 6 & 5 & 5 & 5 & 4 & 5 \\
\hline 7 & 5 & 5 & 5 & 4 & 5 \\
\hline 8 & 5 & 5 & 5 & 4 & 5 \\
\hline 9 & 5 & 5 & 5 & 5 & 5 \\
\hline 10 & 4 & 5 & 4 & 5 & 4 \\
\hline 11 & 3 & 3 & 4 & 5 & 3 \\
\hline 12 & 4 & 5 & 4 & 4 & 5 \\
\hline 13 & 4 & 4 & 5 & 4 & 5 \\
\hline 14 & 5 & 5 & 5 & 5 & 5 \\
\hline 15 & 5 & 5 & 5 & 5 & 4 \\
\hline Jumlah & 70 & 70 & 71 & 70 & 69 \\
\hline & 93, & 93, & 94, & 93, & 92 \\
\hline Persentase & 33 & 33 & 67 & 33 & $\%$ \\
\hline & $\%$ & $\%$ & $\%$ & $\%$ & \\
\hline
\end{tabular}

\begin{tabular}{|c|c|c|c|c|c|}
\hline \multirow{2}{*}{ pernyataan } & \multicolumn{5}{|c|}{ Responden } \\
\cline { 2 - 6 } & $\mathbf{1 1}$ & $\mathbf{1 2}$ & $\mathbf{1 3}$ & $\mathbf{1 4}$ & $\mathbf{1 5}$ \\
\hline 1 & 5 & 5 & 5 & 5 & 5 \\
\hline 2 & 5 & 5 & 5 & 5 & 5 \\
\hline 3 & 5 & 4 & 4 & 5 & 5 \\
\hline 4 & 5 & 5 & 5 & 5 & 5 \\
\hline 5 & 5 & 4 & 4 & 4 & 5 \\
\hline 6 & 5 & 5 & 5 & 5 & 5 \\
\hline 7 & 5 & 5 & 5 & 5 & 5 \\
\hline
\end{tabular}




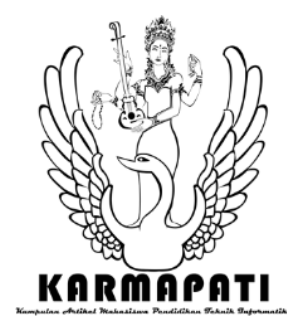

\begin{tabular}{|c|c|c|c|c|c|}
\hline 8 & 5 & 5 & 5 & 5 & 5 \\
\hline 9 & 5 & 5 & 5 & 5 & 5 \\
\hline 10 & 4 & 5 & 5 & 4 & 5 \\
\hline 11 & 3 & 5 & 5 & 4 & 5 \\
\hline 12 & 4 & 5 & 5 & 4 & 4 \\
\hline 13 & 5 & 4 & 4 & 5 & 4 \\
\hline 14 & 5 & 5 & 5 & 5 & 5 \\
\hline 15 & 5 & 5 & 5 & 5 & 4 \\
\hline Jumlah & 70 & 70 & 71 & 70 & 69 \\
\hline & 93, & 93, & 94, & 93, & \multirow{2}{*}{92} \\
Persentase & 33 & 33 & 67 & 33 & $\%$ \\
\hline
\end{tabular}

Respon Guru hasil persentase yang diperoleh keseluruhan subjek dapat disimpulkan bahwa media pembelajaran berbasis augmented reality pada spesifikasi tema gejala alam dapat dikatakan berhasil atau sangat baik mendukung proses pembelajaran.. Masing-masing guru memberikan tanggapan sangat baik terhadap media yang dikembangkan yaitu sebanyak 15 orang. Rata-rata penilaian semua siswa adalah $90,66 \%$

Tabel 7 Respon Guru

\begin{tabular}{|c|c|c|}
\hline \multirow{2}{*}{ pernyataan } & \multicolumn{2}{|c|}{ Responden } \\
\cline { 2 - 3 } & $\mathbf{1}$ & $\mathbf{2}$ \\
\hline 1 & 5 & 5 \\
\hline 2 & 5 & 5 \\
\hline 3 & 4 & 3 \\
\hline 4 & 4 & 5 \\
\hline 5 & 5 & 3 \\
\hline 6 & 4 & 5 \\
\hline 7 & 5 & 5 \\
\hline 8 & 5 & 5 \\
\hline 9 & 5 & 5 \\
\hline 10 & 4 & 3 \\
\hline 11 & 5 & 3 \\
\hline 12 & 5 & 4 \\
\hline 13 & 5 & 4 \\
\hline 14 & 5 & 5 \\
\hline 15 & 5 & 5 \\
\hline Jumlah & 71 & 65 \\
\hline \multirow{2}{*}{ Persentase } & $94,66 \%$ & $86,66 \%$ \\
\hline
\end{tabular}

5. Tahap evaluasi (evaluation) yang meliputi evaluasi formatif dan evaluasi sumatif. Evaluasi formatif dilakukan untuk mengumpulkan data pada setiap tahapan yang digunakan untuk penyempurnaan dan evaluasi sumatif dilakukan pada akhir program untuk mengetahui pengaruhnya terhadap hasil belajar peserta didik dan kualitas pembelajaran secara luas. Penelitian hanya dilakukan evaluasi formatif, karena jenis evaluasi ini
e-ISSN: 2685-7006 |p-ISSN: 2252-9063

Kumpulan Artikel Mahasiswa Pendidikan Teknik Informatika

(KARMAPATI)

Volume 10, Nomor 1, Tahun 2021 berhubungan dengan tahapan penelitian pengembangan untuk memperbaiki produk pengembangan yang dihasilkan.

\section{Kesimpulan}

Hasil rancangan dan implementasi Pengembangan Media Pembelajaran Augmented Reality Book 2 Dimensi Sub Tema Lingkungan Alam untuk siswa PAUD (Studi Kasus: Siswa Kelas A PAUD Telkom Singaraja) menggunakan metode pengembangan ADDIE dengan 5 tahapan yaitu analisis, desain, development, implementasi dan evaluasi.. Pengujian dilakukan melalui white box, black box, Alpha Testing dan Beta Testing. Alpha Testing terdiri uji ahli isi dan uji ahli media untuk mengetahui kevalidan media pembelajaran serta isi media pembelajaran apakah sudah sesuai sehingga media pembelajaran dapat diterapkan. Sedangkan Beta Testing terdiri uji coba perorangan, kelompok kecil dilakukan di kelas B dan uji lapangan dilakukan di kelas A dan respon guru di PAUD Telkom Singaraja.

\section{REFERENSI}

[1] Ananda A (2015). Penerapan Augmented Reality Sebagai Media Pembelajaran Mengenal Planet-Planet Di Tata Surya. Jurnal Sistem dan Teknologi Informasi.

[2] Ayu, I. (2015). Pengembangan Modul Ajar Interaktif Berbasis Augmented Reality Untuk Mata Pelajaran Jaringan Dasar Di Smk Negeri 3 Singaraja. Artikel Mahasiswa Pendidikan Teknik Informatika.

[3] Binanto, I. (2010). Multimedia Digital - Dasar Teori dan Pengembangannya. Yogyakarta: andi.

[4] Candiasa. (2010). Pengujian Instrumen Penelitian Disertasi ITEMAN dan. Singaraja: Universitas Pendidikan Ganesha.

[5] Endra, M. (2013). Augmented Reality Book Sistem Rumah Tradisional Bali Berdasarkan Asta Kosala-Kosali. Nasional Pendidikan Teknik Informatika.

[6] Firmantika, L. (2014). Pengembangan Media Pembelajaran Berbantuan Komputer Untuk Menanamkan Kesadaran Lingkungan Bagi Siswa Smp. Harmoni Sosial, 157.

[7] Gilbert, A. d. (2009). Buku Pintar Perkerja Sosial. Jakarta: PT Bpk Gunung Mulia.

[8] Hardianto. (2005). Media Pendidikan Sebagai Sarana. Majalah Ilmiah Pembelajaran, 101.

[9] Hutomo, A. (2004). PENGEMBANGAN APLIKASI ANDROID KAMUS COMMAND LINE. Yogyakarta: uny.

[10] Kirna, I. M. (2010). Metode Penelitian Pengembangan. Singaraja: Universitas Pendidikan Ganesha.

[11] Kurnia. (2007). Pendidikan Jasmani. Bandung: Grafindo Media Pratama.

[12] Muhson, A. (2010). Pengembangan Media Pembelajaran. Jurnal Pendidikan Akuntansi Indonesia, 3.

[13] Nurseto, T. (2011). Membuat Media Pembelajaran Yang Menarik. Jurnal Ekonomi \& Pendidikan, 19.

[14] Prawiradilaga, D. S. (2008). Prinsip Desain Pembelajaran. Jakarta: Kencana kerjasama dengan Universitas Negeri Jakarta.

[15] Rifa, M. (2014). Penerapan Teknologi Augmented Reality Pada Aplikasi Katalog..

[16] Saputro, E. (2014). Pengembangan Media Pembelajaran Mengenal Organ Pencernaan. Jurnal Buana Informatika, 158. 
e-ISSN: 2685-7006 |p-ISSN: 2252-9063

Kumpulan Artikel Mahasiswa Pendidikan Teknik Informatika

(KARMAPATI)

Volume 10, Nomor 1, Tahun 2021

KARMAPATI

[17] Sugiyono. (2009). Motode Penlitian Kuantitatif, Kualitatif, dan $R \& D$. Alfabeta.

[18] Supratman. (2009). Membandingkan Hasil Belajar Matematika Siswa Yang Pembelajarannya Menggunakan Model Kooperatif Tipe Jigsaw. 191.

[19] Susilana, R. (2008). Media Pembelajaran: Hakikat,Pengembangan,Pemanfaatan Dan Penilaian. Bandung: Wacana Prima.

[20] Wahana. (2010). Panduan Praktis Adobe After Effects. Semarang: Andi.

[21] Winarno. (2015). Membuat Game Android Dengan Unity. Jakarta: Elex.

[22] Wright, A. (2009). Voice-Over for Animation. Burlington: Focal Press.

[23] Zaki. (2015). Pemrograman dan Hack Android. Jakarta: Flex.

[24] Sugihartini, N. (2019). Improving Teaching Ability with Eight Teaching. Advances in Social Science, Education and Humanities Research, 307. 